\title{
Выбор анионообменной мембраны при разделении фенилаланина и хлорида натрия нейтрализационным диализом
}

\author{
® 2020 Сауд А.М. ${ }^{1}$, Васильева В.И. ${ }^{1}$, Голева Е.А. ${ }^{1}$, \\ Акберова Э.М. ${ }^{1}$, Козлов А.Т. ${ }^{2}$ \\ ${ }^{I}$ Воронежский государственный университет, Воронеж \\ ${ }^{2}$ Воронежский военный авиациионый инженерный институт, Воронеж
}

Поступила в редакцию 5.11.2020 г.

DOI: $10.17308 /$ sorpchrom.2020.20/3143

При микробиологическом синтезе фенилаланина полученные смеси, сточные и промывные воды производства содержат помимо целевого компонента также остатки питательной среды, такие как соль и сахар. Для выделения аминокислот из смеси с сахарами и минеральными электролитами используются ионообменные и мембранные технологии.

Нейтрализационный диализ - мембранный процесс деионизации растворов, основанный на принципе доннановского диализа, использующий одновременно катионообменную и анионообменную мембраны и сопровождающийся реакцией нейтрализации. Данная работа посвящена изучению возможности деминерализации раствора фенилаланина нейтрализационным диализом с использованием гетерогенных катионообменной мембраны МК-40 и анионообменных мембран разной основности МА40, МА-41. Установлено, что наиболее эффективное разделение происходит, если показатель кислотности деминерализуемого раствора соответствует изоэлектрической точке аминокислоты, когда она существует в основном в виде биполярного иона. При нейтрализационном диализе растворов смеси минеральной соли и аминокислоты поток минерального компонента превышал поток аминокислоты через все исследованные мембраны во всем диапазоне концентраций. Применение сильноосновной анионообменной мембраны МА-41 в паре с сильнокислотной катионообменной мембраной МК-40 показывает более эффективную деминерализацию по сравнению с использованием среднеосновной анионообменной мембраны МА-40. Степень выделения катионов натрия через сульфокатионообменную мембрану МК-40 составляла 70\%, а хлорид-ионов 48 и 13\% через мембраны МА-41 и МА-40, соответственно.

Установлено, что поток ионов натрия через сильнокислотную катионообменную мембрану МК-40 превышал соответствующие величины для хлорид-ионов через анионообменные мембраны разной основности, что обусловлено различием величин обменной емкости мембран и коэффициентов диффузии противоионов в них. Показано, что при нейтрализационном диализе эквимолярных смесей фенилаланина и хлорида натрия максимальная эффективность разделения компонентов наблюдается в области разбавленных растворов. В канале с мембраной МА-41 по сравнению с мембраной МА-40 большее содержание в деминерализуемом растворе биполярной формы нейтральной аминокислоты приводит к увеличению фактора разделения для мембраны МК-40. С увеличением концентрации исходного раствора происходит снижение фактора разделения как для катионообменной, так и для анионообменных мембран. Максимальные суммарные потери фенилаланина наблюдались в разбавленных смешанных растворах и не превышали 1\%.

Ключевые слова: разделение, деминерализация, нейтрализационный диализ, фенилаланин, хлорид натрия.

\section{Введение}

Процесс нейтрализационного диализа заключается в том, что катионы из секции деионизации могут быть удалены вследствие противодиффузии с ионами $\mathrm{H}^{+}$из 
кислого раствора смежной секции через катионообменную мембрану. С другой стороны, анионы из секции деионизации также могут быть удалены вследствие противодиффузии с ионами $\mathrm{OH}^{-}$из щелочного раствора в смежной секции через анионообменную мембрану. В результате этого, ионы $\mathrm{H}^{+}$и $\mathrm{OH}^{-}$, поступающие в секцию деионизации, вступают в реакцию нейтрализации [1].

Нейтрализационный диализ эффективно применяют при выделении электролитов [2,3], разделении органических электролитов [4], опреснении природной и водопроводной воды [5, 6], разделении слабых кислот и оснований [7], деминерализации водных растворов углеводов и молочной сыворотки [8]. Основным условием эффективной деминерализации растворов аминокислот является обеспечение максимального массопереноса минеральной соли через ионообменные мембраны при сохранении амфолита в исходной секции. Авторами [9] предложен способ деминерализации нейтрализационным диализом смешанного раствора нейтральной аминокислоты и минеральной соли с профилированными гетерогенными ионообменными мембранами МК-40П и МА-40П. Установлено снижение фактора разделения как для катионообменной, так и анионообменной мембран с увеличением концентрации растворов смеси минеральной соли и аминокислоты. Однако, максимальные потери аминокислоты составили менее $0.3 \%$. В работе [10] предложена математическая модель нестационарного процесса очистки раствора аминокислоты от минеральных солей нейтрализационным диализом. Модель адекватно описывает процесс для растворов смеси сильного электролита $\mathrm{NaCl}$ и аминокислоты фенилаланина в случае, когда подвижность аминокислоты в мембранах значительно меньше, чем минеральных солей.

Оптимизация условий для эффективного процесса деминерализации методом нейтрализационного диализа определяется выбором таких параметров как природа и концентрация компонентов, тип ионообменных мембран, показатель кислотности среды и скорости подачи растворов. Целью данной работы является изучение возможности повышения эффективности разделения ароматической нейтральной аминокислоты и минерального электролита нейтрализационным диализом путём целенаправленного подбора ионообменных мембран.

\section{Экспериментальная часть}

Объекты исследования. В качестве ионообменников выбраны гетерогенные сульфокатионообменная мембрана МК-40, анионообменные среднеосновная МА-40 и сильноосновная МА-41 мембраны. Нейтрализационный диализ выполняли с использованием сочетания пар мембран МК-40 и МА-40, МК-40 и МА-41. Физико-химические свойства использованных ионообменных мембран представлены в табл. 1.

Диапазон концентраций смешанных эквимолярных растворов фенилаланина и хлорида натрия составил 0.01-0.15 моль/дм³. В модельных растворах аминокислота находилась преимущественно в виде цвиттер-ионов, так как $\mathrm{pH}$ растворов имел величины, близкие к значению изоэлектрической точки фенилаланина $\mathrm{pI}=5.91$. В исследуемых водных растворах при рН 5.7-6.0 содержание фенилаланина в катионной форме составляло $0.08-0.04 \%$, в анионной $-0.04-0.08 \%$ и биполярной $-99.88 \%$.

Концентрацию фенилаланина определяли спектрофотомерическим методом на спектрофотометре СФ-2000 при $\lambda=259$ нм [11]. Концентрацию натрия измеряли пламенно-фотометрическим методом с помощью прибора ПАЖ-1 [12], хлорид-ионов методом аргентометрического титрования [13]. Для контроля величины $\mathrm{pH}$ растворов использовали лабораторной иономер И-160МИ (Россия) со стеклянным электродом.

Сауд и др. / Сорбционные и хроматографические процессы. 2020. Т. 20. № 6. С. $749-759$ 
Таблица. 1. Физико-химические характеристики исследуемых ионообменных мембран

Table 1. Physicochemical characteristics of the studied ion-exchange membranes

\begin{tabular}{|c|c|c|c|}
\hline Показатель & MK-40 & MA-40 & MA-41 \\
\hline Марка ионита & КУ-2 & ЭДЭ-10П & AB-17 \\
\hline $\begin{array}{c}\text { Ионогенные } \\
\text { группы }\end{array}$ & $\mathrm{R}-\mathrm{SO}_{3} \mathrm{H}$ & $\begin{array}{c}\mathrm{RNH}_{3}^{+}, \mathrm{R}_{2} \mathrm{NH}_{2}^{+}, \\
\mathrm{R}_{3} \mathrm{NH}^{+}, \mathrm{RN}^{+}\left(\mathrm{CH}_{3}\right)_{3} \text { до } \\
20 \% \\
\end{array}$ & $\begin{array}{c}\mathrm{RN}^{+}\left(\mathrm{CH}_{3}\right)_{3} ; \mathrm{R}_{2} \mathrm{NH}_{2}^{+}, \\
\mathrm{R}_{3} \mathrm{NH}^{+} \text {до } 20-25 \%\end{array}$ \\
\hline $\begin{array}{c}\text { Составное повто- } \\
\text { ряющееся звено }\end{array}$ & {$\left[\bigcap_{\mathrm{SO}_{3} \mathrm{H}^{+}}^{-\mathrm{CH}^{-}-\mathrm{CH}_{2}-}\right]_{\mathrm{m}}^{-\mathrm{CH}_{-}-\mathrm{CH}_{2}-} \underbrace{\bigcup_{\mathrm{n}}}_{-\mathrm{CH}-\mathrm{CH}_{2}-}$} & 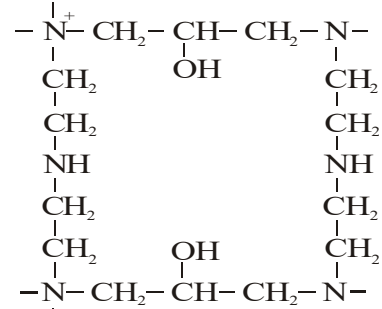 & 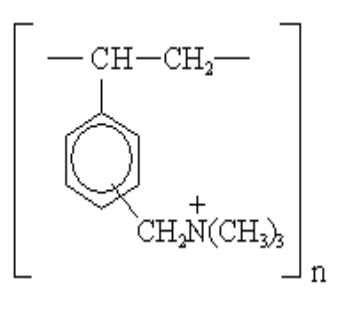 \\
\hline $\begin{array}{c}\text { ПОЕ, } \\
\text { ммоль// } / \text { набух.мемб. }\end{array}$ & $1.58 \pm 0.06$ & $2.92 \pm 0.05$ & $1.18 \pm 0.06$ \\
\hline $\mathrm{W}, \%$ & $38.4 \pm 0.2$ & $37.1 \pm 1.3$ & $31.2 \pm 0.9$ \\
\hline $\mathrm{d}, \mathrm{MKM}$ & $580 \pm 10$ & $540 \pm 20$ & $502 \pm 10$ \\
\hline
\end{tabular}

Обозначения: ПОЕ - полная обменная емкость по 0.1 моль/дм ${ }^{3} \mathrm{NaOH}(\mathrm{HCl})$, ммоль $/ \Gamma_{\text {набух. образца; }} \mathrm{W}-$ влагосодержание, $\mathrm{d}$ - толщина мембраны в набухшем состоянии, $\mathrm{R}$ - радикал полимерной цепи.

Методы исследования. Нейтрализационный диализ проводили в трехсекционной ячейке, показанной на рис. 1. Активная площадь каждой мембраны составляла $7.14 \mathrm{~cm}^{2}(4.2 \mathrm{~cm} \times 1.7 \mathrm{~cm})$, толщина каждой секции диализатора составляла $0.6 \mathrm{~cm}$.

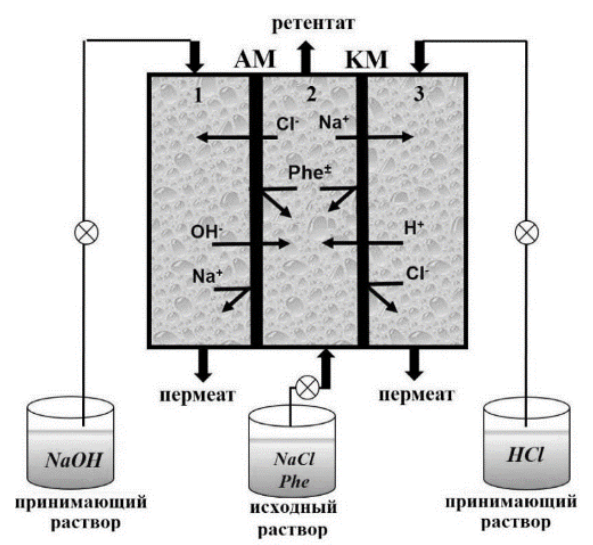

Рис. 1. Схема трехсекционной ячейки при нейтрализационном диализе Fig. 1. Diagram of a three-section cell at neutralization dialysis

Исходные смешанные растворы, раствор кислоты и щёлочи пропускали в режиме противотока. Скорости растворов в секции деминерализации и в соседних секциях составляли $4.5 \times 10^{-2}$ и $5.8 \times 10^{-3} \mathrm{~cm} / \mathrm{c}$, соответственно. Такие скорости были выбраны для получения воспроизводимых результатов измерения концентраций компонентов в стационарном режиме [14]. Для оптимизации условий сохранения значения $\mathrm{pH}$ деминерализуемого раствора в нейтральной области была выбрана концентрация растворов кислоты и щёлочи в принимающем растворе 0.30 моль/дм ${ }^{3}$ [14]. Во время эксперимента собирали фракции для анализа сразу после выхода из приемных секций. По постоянству концентрации компонентов в пробах определяли наступление стационарного состояния. 
Потоки компонентов через исследуемые мембраны определяли по изменению концентраций в растворе пермеата [14]:

$$
J=\frac{C V_{\text {об }}}{S},
$$

где $\mathrm{J}$ - плотность потока компонента, моль $/\left(\mathrm{cm}^{2} \cdot \mathrm{c}\right) ; \mathrm{C}$ - концентрация компонента в растворе пермеата, моль/дм ${ }^{3} ; \mathrm{V}_{\text {об }}$ - объемная скорость раствора в приемной секции, дм ${ }^{3} / \mathrm{c} ; \mathrm{S}$ - активная площадь мембраны, см² $^{2}$.

Эффективность процесса разделения компонентов в смешанном растворе фенилаланина и хлорида натрия оценивали фактором разделения $\mathrm{S}_{\mathrm{F}}$ [15], который определяли как отношение концентраций компонентов в растворе пермеата 1 или 3 к отношению концентраций компонентов в исследуемом растворе, поступающем в среднюю секцию 2:

$$
S_{F}=\frac{\mathrm{C}_{1(3)}(\mathrm{A})}{\mathrm{C}_{1(3)}(\mathrm{Phe})} \div \frac{\mathrm{C}_{2}(\mathrm{~A})}{\mathrm{C}_{2}(\text { Phe })},
$$

где $\mathrm{C}_{1,3}$ - концентрации компонентов в растворе пермеата., $\mathrm{C}_{2}$ - концентрации компонентов в исходном деминерализуемом растворе, Phe - фенилаланин, A - ионы натрия или хлориды.

Расчет степени выделения ионов минеральной соли $\mathrm{R}$ и потерь аминокислоты $\mathrm{L}$ проводился с использованием величин концентрации компонентов в принимающих секциях согласно формулам [15]:

$$
R=\frac{C_{2 i} i}{C_{1 i}} \cdot \frac{V_{2}}{V_{1}} \times 100 \%,
$$

где $\mathrm{C}_{\mathrm{i}}$-концентрация иона, моль/дм ${ }^{3} ; \mathrm{V}$-объемная скорость раствора, дм³/с; индексы 1 и 2 относятся к исходному раствору и пермеату, соответственно;

$$
L=\frac{C(\text { Phe })}{C_{0}(\text { Phe })} \times 100 \%,
$$

где $\mathrm{C}(\mathrm{Phe})$ - концентрация фенилаланина в пермеате, моль/дм ${ }^{3} ; \mathrm{C}_{0}(\mathrm{Phe})$ - концентрация фенилаланина в исходном растворе, моль/дм ${ }^{3}$.

\section{Обсуждение результатов}

Деминерализация. При нейтрализационном диализе раствора смеси минеральной соли и аминокислоты протекают реакции ионного обмена между водородными противоионами катионообменника и катионами металла в растворе, а также между гидроксильными противоионами анионообменника и анионами соли. Ионы натрия (хлорид-ионы) из исходного раствора переходят через катионообменную (анионообменную) мембрану в принимающий раствор, а ионы водорода (гидроксила) кислоты (щелочи) переносятся в противоположном направлении. Поэтому значительному повышению избирательности транспорта минерального компонента и эффективности деминирализации смешанного раствора аминокислоты и соли должно способствовать использование пары сильнокислотной катионообменной и сильноосновной анионообменной мембран по сравнению со среднеосновной анионообменной мембраной МА40. Подтверждение данной гипотезы получено при сравнительном анализе экспериментальных данных по переносу ионов натрия и хлорид-ионов через ионообменные мембраны различной природы и основности. Результаты проведенного исследования представлены в виде зависимостей потоков компонентов от концентрации смешанных эквимолярных растворов (рис. 2).

Установлено, что поток ионов натрия через сильнокислотную катионообменную мембрану МК-40 превышал соответствующие величины для хлорид-ионов через анионообменные мембраны разной основности. По мнению авторов [6] неравенство потоков ионов через мембраны при нейтрализационном диализе обусловлено различием величин обменной емкости мембран и коэффициентов диффузии противоионов

Сауд и др. / Сорбционные и хроматографические процессы. 2020. Т. 20. № 6. С. $749-759$ 
в них. Для мембраны МК-40 характерна более высокая обменная емкость по сравнению с мембранами МА-41 и МА-40 по сильнодиссоциированным группам, а также более высокие величины коэффициентов диффузии противоионов $\overline{\mathrm{D}}_{\mathrm{Na}^{+}}^{\mathrm{MK}-40}=6.92 \times 10^{-11}>\bar{D}_{\mathrm{Cl}^{-}}^{\mathrm{MA}-41}=2.7 \times 10^{-11}>\bar{D}_{\mathrm{Cl}^{-}}^{\mathrm{MA}-40}=2.6 \times 10^{-11} \mathrm{M}^{2} / \mathrm{c} \quad$ и $\bar{D}_{\mathrm{H}^{+}}^{\mathrm{MK}-40}=$ $18.5 \times 10^{-11}>\bar{D}_{\mathrm{OH}^{-}}^{\mathrm{MA}-41}=4.45 \times 10^{-11}>\bar{D}_{\mathrm{OH}^{-}}^{\mathrm{MA}-40}=0.39 \cdot 10^{-11} \mathrm{~m}^{2} / \mathrm{c}[16,17]$.
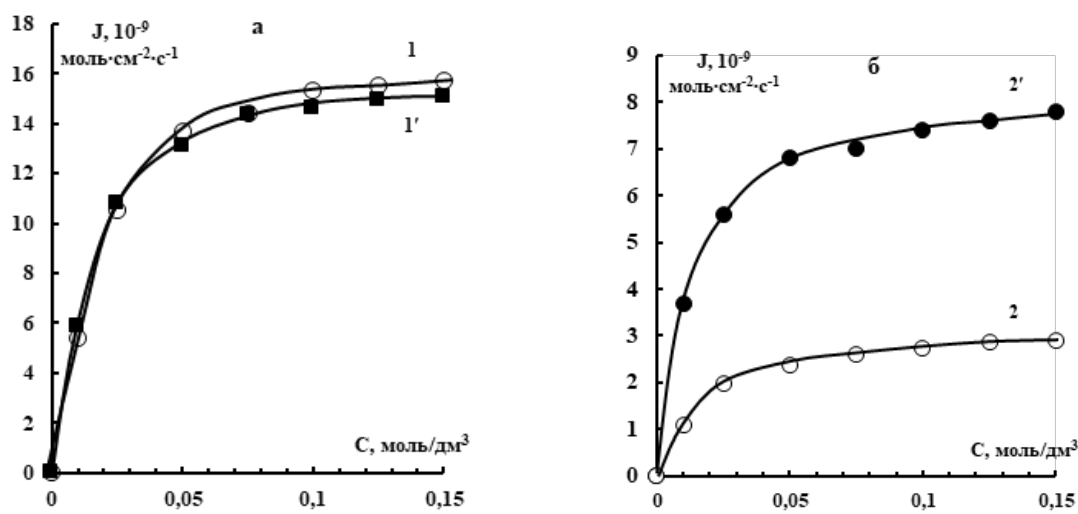

Рис.2. Концентрационные зависимости потоков ионов натрия (а) через мембрану МК-40 в канале с мембраной МА-40 (1) или МА-41 (1') и потоков хлоридионов (б) через мембраны МА-40 (2) и МА-41(2') при нейтрализационном диализе эквимолярных смесей фенилаланина и хлорида натрия.

Fig. 2. Concentration dependences of sodium ion fluxes (a) through an MK-40 membrane in a channel with a MA-40 (1) or MA-41 membrane (1') and fluxes of chloride ions (b) through MA-40 (2) and MA-41 membranes (2') during neutralization dialysis of equimolar mixtures of phenylalanine and sodium chloride.

Установлено, что поток ионов натрия через сульфокатионообменную мембрану МК-40 остаётся практически постоянным при изменении типа анионообменной мембраны (рис.2а). Однако, при использовании сильноосновной мембраны МА-41 вместо мембраны МА-40 поток хлорид-ионов увеличивается в три раза (рис. 2б). Это обусловлено тем, что мембрана МА-40 содержит лишь небольшое количество сильноосновных фиксированных групп (до 20\% четвертичных аминогрупп [18, 19]). В основном в ее состав входят вторичные и третичные аминогруппы. Напротив, большинство фиксированных групп мембраны МА-41 являются сильноосновными четвертичными аминогруппами, а слабоосновные группы могут присутствовать в количестве менее 20-25\% (табл. 1). По мнению авторов [20], при процессе нейтрализационного диализа с анионообменной мембраной, содержащей значительную долю слабоосновных функциональных групп, депротонирование этих групп вызывает увеличение диффузионного сопротивления мембраны и уменьшение поверхностного заряда [21]. Изза уменьшения эффективной обменной емкости доннановское исключение коионов уменьшается. В результате этого, концентрация коионов в анионообменной мембране существенно увеличивается, вызывая увеличение потока этих ионов в исходную секцию, затрудняя процесс деминерализации и вызывает подкисление водно-солевого раствора аминокислоты.

Кроме того, использование анионообменных мембран МА-41 и МА-40 оказывает разное влияние на $\mathrm{pH}$ раствора в секции деминерализации (рис. 3). Известно, что при нейтрализационном диализе значение $\mathrm{pH}$ определяется отношением концентраций $\mathrm{H}^{+}$и $\mathrm{OH}^{-}$в секции деминерализации, которое зависит от соотношения коэффициентов диффузии ионов, толщины не перемешиваемых слоев, прилегающих к поверх- 
ности мембраны, и от начальных концентраций кислотных, щелочных и деминерализуемых растворов [3]. Вследствие более высокого переноса ионов гидроксила через мембрану МА-41 деминерализуемый раствор закислялся в меньшей степени и во всем диапазоне концентраций значение $\mathrm{pH}$ составляло 5.0-5.6. Значения $\mathrm{pH}$ деминерализуемого раствора при использовании мембраны смешанной основности МА-40 падало до величин 4.0-5.1.

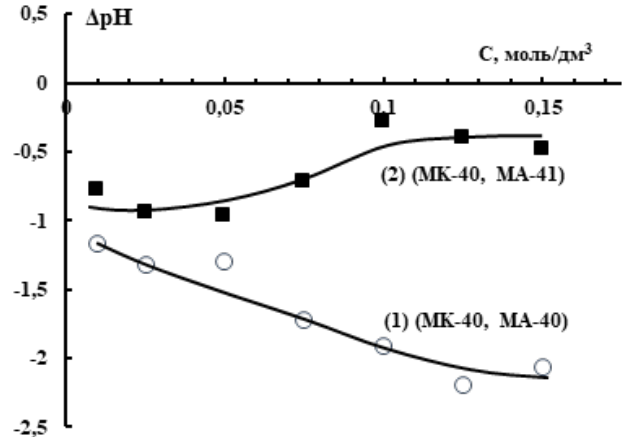

Рис. 3. Зависимость разности $\mathrm{pH}$ растворов на выходе и входе секции деминерализации, образованной катионообменной мембраной МК-40 и анионооб-

менными мембранами МА-40 (1) и MA-41 (2) от концентрации смешанного эквимолярного раствора фенилаланина и хлорида натрия.

Fig. 3. Dependence of the $\mathrm{pH}$ difference of solutions at the outlet and inlet of the demineralization section formed by the MK-40 cation-exchange membrane and the MA-40 (1) and MA-41 (2) anion-exchange membranes on the concentration of a mixed equimolar solution of phenylalanine and sodium chloride.

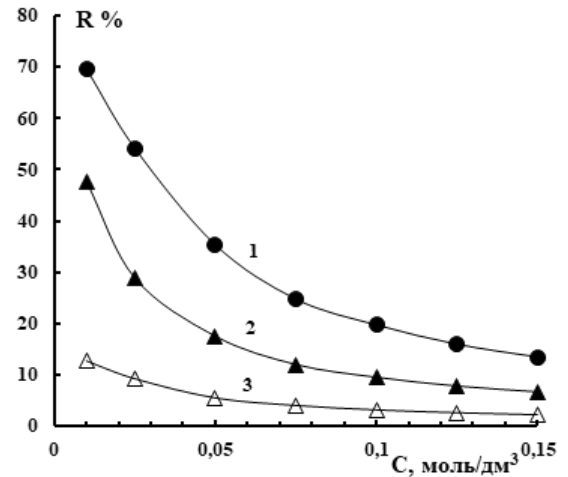

Рис. 4. Концентрационные зависимости степени выделения ионов электролита при нейтрализационном диализе эквимолярных смешанных растворов фенилаланина и хлорида натрия через мембраны МК-40 (1), MA-41 (2) и МА-40 (3).

Fig. 4. Concentration dependences of the degree of release of electrolyte ions during neutralization dialysis of equimolar mixed solutions of phenylalanine and sodium chloride through MK-40 (1), MA-41 (2), and MA-40 (3) membranes.

При нейтрализационном диализе смешанных эквимолярных растворов фенилаланина и хлорида натрия установлено уменьшение степени выделения ионов электролита с увеличением концентраций исходного раствора (рис. 4). Максимальная эффективность деминерализации наблюдалась в разбавленных растворах. Степень выделения при концентрации раствора 0.01 моль/дм ${ }^{3}$ составляла для ионов натрия $70 \%$. При увеличении концентрации раствора в пятнадцать раз установлено уменьшение степени выделения катионов натрия в пять раз. Во всем диапазоне концентраций степень выделения катионов через мембрану МК-40 превышала выделение анионов через анионообменные мембраны. При этом степень выделения анионов соли через мембрану МА-41 превышала соответствующие значения для мембраны МА-40 и составляла 48 и $13 \%$.

Разделение. Возможность разделения нейтрализационным диализом амфолита и сильного электролита достигается вследствие их различной природы. Установлено, что при нейтрализационном диализе потоки минерального электролита через мем- 
браны (рис. 2) значительно превышали потоки аминокислоты (рис. 5). Основной причиной является создание условий сохранения амфолита фенилаланина $(\mathrm{pI}=5.91)$ в биполярной форме в исходном деминерализуемом растворе.

Выявлено, что потоки фенилаланина через сульфокатионообменную мембрану МК-40 в канале, образованном с сильноосновной мембраной МА-41, меньше соответствующих значений в случае мембраны МА-40 во всем диапазоне концентраций (рис. 5а). Причиной является менее резкое закисление деминерализуемого раствора при использовании сильноосновной мембраны МА-41 (рис. 3). В результате, при использовании в паре с мембраной МК-40 мембран МА-41 и МА-40 в деминерализуемом растворе находилось в виде биполярных ионов 99.6-99.9\% и 96.3-99.2 \% фенилаланина, соответственно.
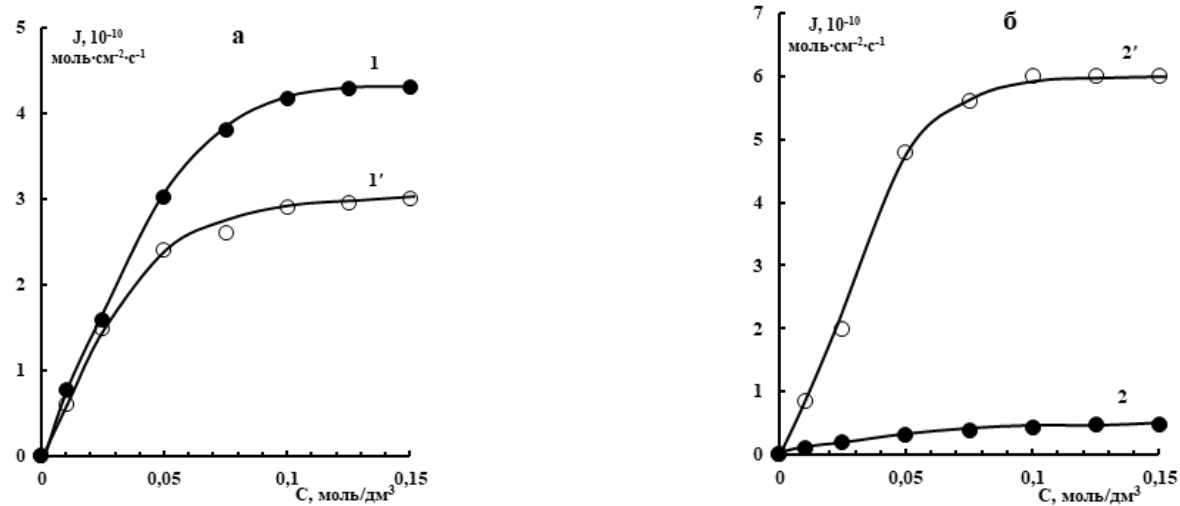

Рис. 5. Концентрационные зависимости потоков фенилаланина через катионообменную мембрану МК-40 (а) в канале с мембраной МА-40 (1) или МА-41 (1') и через анионообменные мембраны (б) МА-40 (2), МА-41(2') при нейтрализационном диализе эквимолярных смешанных растворов фенилаланина и хлорида натрия.

Fig. 5. Concentration dependences of phenylalanine fluxes through a MK-40 cation-exchange membrane (a) in a channel with a MA-40 (1) or MA-41 (1') membrane and through MA-40 (2) and MA-41 (2') anion-exchange membranes (b) during neutralization dialysis of equimolar mixed solutions of phenylalanine and sodium chloride.

Зависимость фактора разделения $\mathrm{S}_{\mathrm{F}}$, рассчитанная по выражению (2), от концентраций смешанных эквимолярных растворов фенилаланина и хлорида натрия представлена на рис.6. Установлено, что с увеличением концентрации исходного смешанного раствора происходит снижение фактора разделения как для катионообменной, так и для анионообменных мембран.

Большее содержание биполярной формы нейтральной аминокислоты фенилаланина приводит к увеличению фактора разделения для мембраны МК-40 (рис. 6) С другой стороны, вследствие переноса из принимающих растворов ионов водорода через катионообменную и ионов гидроксила через анионообменную мембраны происходят протолитические реакции этих ионов с фенилаланином в диффузионных пограничных слоях каждой мембраны. Через сильноосновную мембрану МА-41 ионы гидроксила переносятся в большей степени по сравнению с мембраной МА-40. В результате этого фенилаланин реагирует с ионами водорода (ионами гидроксила), переходит в катионную (анионную) форму и переносится через соответствующие мембраны. В результате такого механизма потери аминокислоты для сильноосновной мембраны МА-41 больше, чем для мембраны смешанной основности МА-40 (табл. 2). 


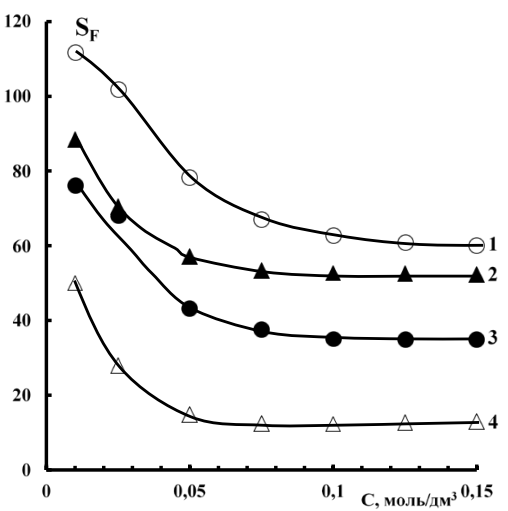

Рис. 6. Концентрационные зависимости фактора разделения фенилаланина и хлорида натрия для анионообменных мембран МА-40 (1), МА-41 (4) и катионообменной мембраны МК-40 в канале с мембраной МА-41 (2) и МА-40 (3) при нейтрализационном диализе эквимолярных смешанных растворов.

Fig. 6. Concentration dependences of the separation factor of phenylalanine and sodium chloride for MA-40 (1) and MA-41 (4) anion-exchange membranes and the MK-40 cation-exchange membrane in a channel with a MA-41 (2) or MA-40 (3) membrane during neutralization dialysis of equimolar mixed solutions.

Таблица. 2. Потери аминокислоты при нейтрализационном диализе.

Table 2. Loss of amino acids during neutralization dialysis.

\begin{tabular}{|c|c|c|c|c|}
\hline \multirow{2}{*}{$\begin{array}{c}\mathrm{C}_{0}(\mathrm{Phe})=\mathrm{C}_{0}(\mathrm{NaCl}), \\
10^{-2} \text { моль } / \text { дм }\end{array}$} & \multicolumn{4}{|c|}{$\mathrm{L}, \%$} \\
\hline 1.0 & МК-40 (MA-40) & MA-40 & MK-40 (MA-41) & MA-41 \\
\hline 2.5 & 0.92 & 0.12 & 0.72 & 0.93 \\
\hline 5.0 & 0.84 & 0.10 & 0.62 & 0.80 \\
\hline 7.5 & 0.72 & 0.07 & 0.54 & 0.63 \\
\hline 10.0 & 0.61 & 0.06 & 0.37 & 0.47 \\
\hline 12.5 & 0.50 & 0.05 & 0.28 & 0.40 \\
\hline 15.0 & 0.41 & 0.05 & 0.23 & 0.34 \\
\hline & 0.34 & 0.04 & 0.19 & 0.29 \\
\hline
\end{tabular}

При нейтрализационном диализе смешанных эквимолярных растворов фенилаланина и хлорида натрия максимальные суммарные потери фенилаланина наблюдались в разбавленных смешанных растворах и не превышали $1 \%$, что значительно ниже установленных при электродиализе в гладких каналах. В работе [22] суммарные потери фенилаланина за счёт массопереноса через катионообменную МК-40 и анионообменную МА-41 мембраны при электродиализе смешанного раствора с хлоридом натрия $\left(\mathrm{C}_{0}(\mathrm{Phe})=0.02\right.$ моль/дм $\mathrm{M}^{3}, \mathrm{C}_{0}(\mathrm{NaCl})=0.01$ моль/дм $\left.{ }^{3}\right)$ при плотности тока $5.0 \mathrm{MA} \cdot \mathrm{cm}^{-2}$, обеспечивающей наибольшее обессоливание раствора $(\mathrm{R}=87 \%)$, составили $15.5 \%$.

\section{Заключение}

Установлено, что нейтрализационный диализ смешанных растворов фенилаланина и хлорида натрия характеризуется большими величинами фактора разделения компонентов, степенями выделения минеральных ионов и незначительными потерями фенилаланина за счет прохождения реакции нейтрализации в деминерализуемом растворе и преимущественного нахождения аминокислоты в биполярной форме. Показано, что выделение нейтральной аминокислоты из смеси с минеральной солью 
наиболее эффективно из разбавленных растворов с использованием в мембранном канале сильнокислотной и сильноосновной ионообменных мембран.

Работа выполнена при финансовой поддержке РФФИ (проект № 18-08-01260).

\section{Список литературы}

1. Sato K., Yonemoto T., Tadaki T. // J. Chem. Eng. Jpn. 1993. Vol. 26. pp. 68-74.

2. Igawa M., Mikami K., Okochi H. // Bull. Chem. Soc. Jpn. 2003. Vol. 76. pp. 437-441.

3. Tishchenko G.A., Denisov G.A., Shataeva L.K., M. Bleha // Collect. Czech. Chem. Commun. 1995. Vol. 60. pp. 1888-1904.

4. Kimura Y., Yamada K. // Int. J. Mater. Sci. Appl. 2018. Vol. 7, pp. 95-105.

5. Chérif M., Dammak L., Mkacher I., Ghalloussi R. // Desalin. Water Treat. 2015. Vol. 56. pp. 2567-2575.

6. Chérif M., Mkacher I., Dammak L., Salah A.B., Nikonenko. V.// Desalination. 2015. Vol. 361, pp. 13-24.

7. Tanabe H., Okochi H., Igawa M. // Ind. Eng. Chem. Res. 1995. Vol. 34. pp. 2450-2454.

8. Bleha M., Tlshchenko G.A. // J. Membr. Sci. 1992. Vol. 73. pp. 305-311.

9. Васильева В.И, Голева Е.А., Заболоцкий В.И., Селеменев В.Ф. и др. Патент РФ. № RU2607227C1. 2015.

10. Kozmai A., Goleva E., Vasil'eva V., Nikonenko V. et al. // Membranes. 2019. Vol. 9. pp. 171-186.

11. Котова Д.Л., Крысанова Т.А., Елисеева Т.В. Спектрофотометрическое определение аминокислот в водных растворах. Воронеж. ВГУ. 2004. $55 \mathrm{c.}$

12. Saud A.M., Smagin M.A., Vasil'eva V.I. // Заводская лаборатория. Диагностика материалов. 2020. Vol. 86. pp. 13-18.
13. Калюкова Е.Н. Титриметрические методы анализа. Ульяновск. УлГТУ. 2008. 108 c.

14. Васильева В.И., Голева Е.А. // Журнал физической химии. 2013. Т. 87. № 11. С. 1925-1931.

15. Хванг С.-Т, Каммермейер К. Мембранные процессы разделения. М. Химия. 1981. $464 \mathrm{c}$.

16. Голева Е.А. Дисс. канд. хим. наук. Воронеж. 2017. $172 \mathrm{c}$.

17. Шапошник В.А. Кинетика электродиализа. Воронеж. ВГУ. 1989. 176 с.

18. Zyryanova S.V., Pismenskaya N.D., Nikonenko V.V. // Petroleum Chemistry. 2018. Vol. 58. No 11. pp. 965-974.

19. Васильева В.И., Письменская Н.Д., Акберова Э.М., Небавская К.А. // Журнал физической химии. 2014. Т. 88. № 7-8. С. 1114 1120.

20. Kozmai A., Nikonenko V., Pismenskaya N., Dammak L. et al. // J. Membr. Sci.. 2020. Vol. 595. Art. No 117573.

21. Kozmai A.E., Nikonenko V.V, Zyryanova S., Pismenskaya N.D. et al. // J. Membr. Sci. 2018. Vol. 567, pp. 127-138.

22. Харина А.Ю., Елисеев С.Я. // Конденсированные среды и межфазные границы. 2017. T. 19. № 1. C. 126-132.

\title{
Selection of anion-exchange membrane for separation of phenylalanine and sodium chloride by neutralization dialysis
}

\author{
(C) 2020 Saud A.M. ${ }^{1}$, Vasil'eva V.I. ${ }^{1}$, Goleva E.A. ${ }^{1}$, \\ Akberova E.M. ${ }^{1}$, Kozlov A.T. ${ }^{2}$ \\ ${ }^{I}$ Voronezh State University, Voronezh \\ ${ }^{2}$ Voronezh Military Aviation Engineering Institute, Voronezh
}

In the microbiological synthesis of phenylalanine, the resulting mixtures, waste and wash waters of production, in addition to the target component, also contain residues of the nutrient medium, such as salt and 
sugar. For isolation of amino acids from a mixture with sugars and mineral electrolytes, ion exchange and membrane technologies are used.

Neutralization dialysis is a membrane process of deionization of solutions based on the principle of Donnan dialysis, using both cation-exchange and anion-exchange membranes and accompanied by a neutralization reaction. In this work, the possibility was investigated of demineralizing a phenylalanine solution by neutralization dialysis using a MK-40 heterogeneous cation-exchange membrane and MA-40 and MA-41 anion-exchange membranes of different base strengths. It was found that the most effective separation occurs if the acidity index of the demineralized solution corresponds to the isoelectric point of the amino acid, when it exists mainly in the form of a bipolar ion. During the neutralization dialysis of solutions of a mixture of mineral salt and amino acid, the flux of the mineral component exceeded the flux of the amino acid through all the studied membranes in the entire concentration range. The use of a MA-41 strongly basic anion-exchange membrane together with a MK-40 strongly acidic cation-exchange membrane demonstrated more efficient demineralization compared to the use of a MA-40 medium-basic anion-exchange membrane. The degree of release of sodium cations through the MK-40 sulphonic cation-exchange membrane was $70 \%$, and for chloride ions it was $48 \%$ and $13 \%$ through the MA-41 and MA-40 membranes, respectively.

It was found that the flux of sodium ions through a strongly acidic cation-exchange membrane MK40 exceeded the corresponding values for chloride ions through anion-exchange membranes with different base strengths, which was due to the difference in the exchange capacity values of membranes and the diffusion coefficients of counterions in them. It was shown that during the neutralization dialysis of equimolar mixtures of phenylalanine and sodium chloride, the maximum efficiency of separation of components was observed in the region of dilute solutions. In the channel with the MA-41 membrane, in comparison with the MA-40 membrane, the higher content of the bipolar form of the neutral amino acid in the demineralized solution led to an increase in the separation factor for the MK-40 membrane. As the concentration of the initial solution increased, the separation factor decreased for both the cation-exchange and anion-exchange membranes. The maximum total loss of phenylalanine was observed in dilute mixed solutions and did not exceed $1 \%$.

Keywords: separation, demineralization, neutralization dialysis, phenylalanine, sodium chloride.

\section{References}

1. Sato K., Yonemoto T., Tadaki T., J. Chem. Eng. Jpn., 1993, Vol. 26, pp. 68-74.

2. Igawa M., Mikami K., Okochi H., Bull. Chem. Soc. Jpn., 2003, Vol. 76, pp. 437-441. DOI: $10.1246 /$ bcsj. 76 .

3. Tishchenko G.A., Denisov G.A., Shataeva L.K., Bleha M., Collect. Czech. Chem. Commun., 1995, Vol. 60, pp. 1888-1904. DOI: $10.1135 / \operatorname{cccc} 19951888$

4. Kimura Y., Yamada K., Int. J. Mater. Sci. Appl., 2018, Vol. 7, pp. 95-105. DOI: 10.11648/j.ijmsa.20180703.14

5. Chérif M., Dammak L., Mkacher I., Ghalloussi R., Desalin. Water Treat., 2015, Vol. 56, pp. 2567-2575.

6. Chérif M., Mkacher I., Dammak L., Salah A.B. et al., Desalination, 2015, Vol. 361, pp. 13-24. DOI: 10.1080/19443994.2015.1076350

7. Tanabe H., Okochi H., Igawa M., Ind. Eng. Chem. Res., 1995, Vol. 34, pp. 2450-2454. DOI: 10.1021/ie00046a028

8. Bleha M., Tlshchenko G.A., J. Membr. Sci., 1992, Vol. 73, pp. 305-311. DOI: 10.1016/03767388(92)80137-9

9. Vasil'eva V.I., Goleva E.A., Zabolockij V.I., Selemenev V.F. et al. Patent RF, no. RU2607227C1, 2015.
10.Kozmai A., Goleva E., Vasil'eva V., Nikonenko V. et al., Membranes, 2019, Vol. 9, pp. 171-186. DOI: 10.3390/membranes9120171w

11.Kotova D.L., Krysanova T.A., Eliseeva T.V. Spectrophotometric determination of amino acids in aqueous solutions. Voronezh, Voronezh State University, 2004, 55 p.

12.Saud A.M., Smagin M.A., Vasil'eva V.I., Industrial laboratory. Diagnostics of materials, 2020, Vol. 86, pp. 13-18. DOI: 10.26896/10286861-2020-86-1-13-18

13.Kaljukova E.N. Titrimetric methods of analysis. Ulyanovsk, U1GTU, 2008, 108 p.

14. Vasil'eva V.I., Goleva E.A., Journal of Physical Chemistry, 2013. Vol. 87, No 11, pp. 1925-1931.

15.Khvang S.-T, Kammermejer K. Membrannye processy razdelenija. M., Khimia Publ., $1981,464 \mathrm{p}$.

16.Goleva E.A. Diss. cand. chem. nauk. Voronezh, 2017, 172 p.

17.Shaposhnik V. A. Kinetics of electrodialysis. Voronezh, VSU, 1989, 176 p.

18.Zyryanova S.V., Pismenskaya N.D., Nikonenko V.V., Petroleum Chemistry, 2018, Vol. 58, No 11, pp. 965-974. DOI: $10.1134 / \mathrm{S} 0965544118110087$ 
19. Vasil'eva V.I., Pismenskaya N.D., Akberova E.M., Nebavskaya K.A., Russ. J. Phys. Chem., 2014, Vol. 88, No 7-8, pp. 1114-1120. DOI: $10.1134 / \mathrm{S} 0036024414080317$

20.Kozmai A., Nikonenko V., Pismenskaya N., Dammak L. et al., J. Membr. Sci., 2020, Vol. 595, Art. No 117573. DOI: 10.1016/j.memsci.2019.117573

Сауд Али Мунир - аспирант кафедры аналитической химии химического факультета, Воронежский государственный университет, Воронеж

Васильева Вера Ивановна - д.х.н., профессор кафедры аналитической химии химического факультета, Воронежский государственный университет, Воронеж

Голева Елена Алексеевна - к.Х.н., ведущий инженер, Юго-Восточная химико-техническая лаборатория - структурное подразделение Юго-Восточной железной дороги филиала ОАО РЖД, Воронеж

Акберова Эльмара Маликовна - к.Х.н., ведущий инженер кафедры аналитической химии, Воронежский государственный университет, Воронеж

Козлов Александр Тимофеевич - д.б.н., проф., зав. кафедрой экологии, Воронежский военный авиационный инженерный институт, Воронеж
21.Kozmai A.E., Nikonenko V.V, Zyryanova S., Pismenskaya N.D. et al., J. Membr. Sci., 2018, Vol. 567, pp. 127-138. DOI: 10.1016/j.memsci.2018.07.007

22.Kharina A.Yu., Eliseev S.Ya., Condensed media and interphase boundaries, 2017, Vol. 19, No 1, pp. 126-132.

Saud Ali M. - postgraduate student of the Analytical Chemistry Department, Voronezh State University, $\quad$ Voronezh, e-mail: alisaud1900@live.com

Vasil'eva Vera I. - Dr. Sci. (Chem.), the professor of the Analytical Chemistry Department, Voronezh State University, Voronezh, e-mail: viv155@mail.ru

Goleva Elena A. - $\mathrm{PhD}$ (Chem.), leading engineer, South-Eastern chemical-technical laboratory, structural unit of the South-Eastern railway a branch of Russian Railways, Voronezh, e-mail: vorobjeva_ea@mail.ru

Akberova Elmara M. - PhD (Chem.), leading engineer of the Analytical Chemistry Department, Voronezh State University, Voronezh, e-mail: elmara 09@inbox.ru

Kozlov Alexander T. - Ph. D., prof., Head. Department of Ecology, Voronezh Military Aviation Engineering Institute, Voronezh 